still drowsy, but better. I desired the friends to continue the treatment, and bring the child to me in the evening, which they did, perfectly recovered.

Observe, this practice should be continued, according to circumstances, from three to twelve hours. (See "Christison's Medical Jurisprudence.") The patient should be also occasionally roused, even when he may be allowed to sleep, in order to be sure of his recovery.

CASE 2.-The other case is that of a female-she might be about 50 years of age, who having suffered domestic trouble took laudanum, with the intent to commit suicide, in the following manner:-Between seven and eight o'clock in the evening she went out and bought two-pennyworth (as she said) of laudanum, which, as soon as she was ont of the shop, she swallowed; she then went to another shop and bought three-penny worth, which she made use of in the same way; she afterwards went to a third shop in the neighbourhood, and bought two-pennyworth more, but paused a few minutes before taking it, and conversed with some acquaintance whom she accidentally met, but as soon as that person left her she took the remaining dose, and returned home, keeping what she had done a secret from her family. At length, however, her son perceiving something irregular in her manner, began to converse with her about herself, and finding him importunate, confessed that she had taken opium. He then went for medical assistance, but could not procure any until ten o'clock, when two medical attendants arrived, one soon after the other, and tried the stomach-pump, but did not bring anything away that at all satisfied them as to the presence of opium.

Finding her now in a state of great stupor, two persons were employed to shake her whilst sitting in her chair, but with little effect. One of these "gentlemen came to me requesting $m y$ assistance. Although $I$ attended immediately, I did not arrive until past 11, P.M., when I suggested that her feet should be put as soon as possible into hot water, and the head, neck, and chest bathed alternately with hot and cold water, while acidulous tuids, ammonia, \&c., should be given internally. When $I$ found that these means were losing their influence, $I$ directed that the feet should be placed in cold water: this, as might be expected, produced a sudden and powerful effect; but it should be particularly observed that the feet should not be allowed to remain above a few seconds at a time in the cold, for the reasons mentioned above, in speaking of the warm bath; they were consequently soon replaced in the bucket containing the warm water. After persevering in this plan for rather more than two hours, the patient recovered so far as to converse a little; $I$ then directed that she should be wiped dry and rubbed, still continuing the fluids internally, and that if she was found to relapse at all, to bathe her again; but in a short time she was so far cognisant, as to insist upon being placed by the fire, and soon after went to bed. I may add, that, perhaps a little is due to the fact that some of the fluids given internally with a large spoon, having accidentally gone the wrong way, made her cough.

$I$ trust that these two cases are sufficiently illustrative of the power which we gain by such a plan of treatment, and of the utility of making it public, since in the first the practitioner had no hope, and in the second one of the medical attendants thought pro. per to call in further assistance. I may also mention (to show how even well-informed persons may lose sight of the principle here inculcated) that the other medical man attending this last case exclaimed, when he saw what I was doing, "That is Christison's plan, is it not?" Besides, I would observe, that although occasional rousing by physical force or shaking may be useful, it requires great exertion on the part of the attendants, who may be difficult to procure; and it is also very fatiguing and painful to the patient, and if not continued most unremittingly, it is, I am inclined to think, apt to confirm the stupor rather than relieve it. $\mathbf{A}$ farther apology, Sir, for having taken up so much of your valuable time, when we may save a few lives, is, I feel assured, unnecessary. I am, Sir, yours, \&c.,

Theodore T. G. Boigragon, M.D.

5 , Princes-street, Hanover-square, Feb. 26, 1840.

\section{DISEASES OF THE SKIN.}

By Erasmus Wilson, Esq., Consulting Surgeon to the St. Pancras Infirmary.

\section{ECZEMA IMPETIGINODES.}

Case 1.-On the 1st of February I was requested by my brother to see Margaret Cunningham, a delicate child, aged six years, who was suffering from a severe attack of this painful affection. She was feverish; her pulse quick; tongue white and dry; sleep at night much disturbed, and digestive organs disordered. About three weeks since, the disease first made its appearance in the palm of the right hand, in the form of a cluster of eczematous vesicles, which quickly became confluent, and formed an irregular milky vesicle, of considerable size. In a day or two the contents of the vesicle assumed a purulent character; the cuticle was softened and rubbed off, and the exposed cutis presented a bright carmine-coloured 
gecreting surface. This pustule was succeeded by successive crops of vesicles, of various size, which went rapidly through the sero-purulent stages, and terminated in the same manner with the first.

At the period of my first seeing her, both hands were covered with serous and seropurulent vesicles and pustules, each surrounded by a highly - inflamed base, of variable size, and extending for two-thirds up the fore-arm. On some parts of the fingers were clusters of small vesicles of eczema simplex, withont any inflammatory halo; around the roots of the nails were large pustular surfaces, highly inflamed, and much swollen. Upon the sides of the fingers the soddened cuticle had been torn or rubbed off, and the exposed and carmine-coloured cutis was secreting a very large quantity of irritating and offensive ichorous flaid. On the palmar surface of the fingers were several broad and flattened sero-pustules; while on the dorsum of the fingers and hands serous vesicles were confusedly intermingled with true impetiginous pustules. On the fore-arm were several vesicles of eczema rubrum, and a few small pustules of impetigo; and at the flexures of the wrist and elbow was an extensive crop of vesicles of eczema simplex. Numerous small discreet vesicles of eczema were likewise dispersed over the surface of ber body.

I ordered for her a local steam bath; warm fomentations, poultices at night, and aperient medicine.

On the 6th of February, hearing that the child had been taken by her mother, as an out-patient, to the Hospital, I again called upon her, and was informed that she had been seen by the surgeon in attendance, who pronounced the disease to be a very bad case of itch, and prescribed the compound sulphur ointment to be rubbed upon the hands. On requesting to see the patient, I found her crying, and in extreme pain; she had en. dured an agony of suffering during the night, and had obtained no sleep. Her hands and arms were swollen, highly inflamed, and a numerous crop of true impetiginous pustules extended from the backs of the hands upwards to the elbows.

I immediately washed away with warm water every trace of the sulphur ointment, and had the hands well fomented with an infusion of linseed, desiring the mother to soak and foment them again at night, to keep them supported above the level of the body, and to place them in a large poultice.

On the following day the appearance of the hands was much improved; the inflammatory action had greatly subsided, and the skin was less tense and painful. The treatment was attentively pursued until the 8 th, when I again called, and found the child crying, and in much pain. Upon inquiry, I learnt that she had been taken to the hospital during the day; that the surgeon had expressed his satisfaction at the improved appearance of the hands, and had praised the effects of the ointment, desiring a continued application; and that, acting upon this order, the mother had actually bedaubed the excoriated surfaces with this irritating com. pound a few hours previously.

The mother was now so much frightened at the painful effects which she had been the means of causing, by inattention to my instructions, that sbe declared she would go no more to the hospital if I would undertake the treatment of the case. I accordingly had the hands freed from the unguent, and well fomented; and, after the fomentation, anointed with olive-oil, containing the liquor plumbi in the proportion of half a drachm to the ounce; the poultices to be continued every night.

On the following days, the fomentations were continued night and morning, and in the interval of the fomentations the hands were enclosed in soft linen rags, wetted with warm water, and enclosed in oil-silk. From this time the case went on progres. sively, and rapidly improving; fresh crops of impetiginous pustules appeared from time to time, but each successive crop consisted of pustules smaller and fewer in number than the preceding; and on the 26th of February she was quite cured, the cuticl having exfoliated from off the entire surface of both hands and part of the arms, and being re. placed by a new and thin epidermis.

Case 2.-A gentleman, about 35 years of age, labouring under the same disease, presented himself for my adpice on the \%th of February. He had been advised to use some sulphur ointment, which he proposed to rub upon his hands the same evening. Reminded of the effects of this ointment, particularly the compound preparation, in the preceding case, as well as in several others of the same kind, in which I have seen it applied, I was not unwilling that he should make the trial, particularly as he wished it himself, in order that I might have further proof of its irritating power. On the following morning he said be had suffered so much pain during the uight, as wholly to deprive him of sleep; the hands were highly inflamed and much swollen, and several new sero-purulent vesicles had appeared. The disease was confined to the backs of the hands, and to the dorsal surface and iuner sides of the fingers, which were particularly affected around the roots of the nails, and on one finger a sero-pustule was seen immediately beneath the nail. On the backs of the hands the disease existed in all its stages; in one place was the small, in. flamed, and somewhat raised patch upon which the vesicle would make its appearance ; in another, the vesicle, cellular in structure, and apparently formed by the con. flicence of numerous small eczematous vesi- 
cles, was fully developed; in a third place, the transparent serous fluid had become opaque and milky; and in a fourth perfectly purulent; while in certain situations the softened cuticle had been rubbed off, and displayed the highly vascular surface of the cutis, from which a large quantity of irritating ichorous fluid was discharged.

I ordered him the local steam baths, and fomentations of warm water, which he used assiduously, and enveloped the hands, in the intervals of this treatment, in lint dipped in warm water and oiled silk,-the common water dressing; administering at the same time a tonic-aperient medicine to regulate the digestive functions.

New crops of impetiginous pustules, of small size, and few in number, appeared from time to time; the disease rapidly im. proved, and on the 20 th of February he was quite cured.

Upper Charlotte-street, Fitzroy-square.

TREATMENT OF

\section{DISEASE OF THE HIP-JOINT, BY}

\section{SALIVATION WITH MERCURY.}

\section{To the Editor of THE LANCET.}

SIR :-The treatment of morbus coxz by rapidly mercurialising the system, which originated with me, is not, it would seem, much known in Eugland, although it has now been nearly six years before the profession, and has proved strikingly successful, not only in my hands, but in those of Lis. franc,* Carmichael, $\uparrow$ Sir Philip Crampton, Dr. Bellingham, Professor Porter, and others. I trust, therefore, that you will give insertion to the inclosed letter, containing two cases, which are very well detailed, and which appear to me to be valuable in other respects. For example, it will be seen that in these cases the patients resumed, with impunity, their usual occupations in less than a fortnight after the commencement of the plan ot treatment, and without either that confinement to the horizontal posture, or the use of sarsaparilla, for weeks, which I have hitberto thought absolutely necessary, but which much more extended observation can alone induco me to relinquish. Other circumstances, however, are observable in these cases, which call for some practical observations from me :-

In the first place, I do not give purgatives, in order that the combination of calomel and opinm may more quickly affect the mouth.

* See Lancer for 1834-5, vol. ii., p. 174, et seq.

† "Dublin Medical Press" for January 8 th, 1840.
Secondly, I do not apply leeches, or make use of cupping.

Thirdly, I do not apply blisters, or use any kind of counter-irritation, until ptyalism has declared itself.

Fourthly, I confine the patient to the horizontal position, and give, daily, either a pint or half a pint of the compound infusion of sarsaparilla, for three weeks or more, according to the standing or intensity of the disease. I have the honour to be, Sir, your obedient, humble servant,

$$
\text { James O'Betrne, M.D., \&c. }
$$

“To James O'Berrne, M.D., SurgeonExtraordinary to the Queen.

"Dear Sir:-Two cases of morbus $\operatorname{cox} x$, in the first stage, having presented themselves, I adopted the treatment which originated with, and was first employed by, you with success, in the Richmond Surgical Hospital. I beg leave to forward to you a report of their history, and ramarkably favourable issue, as a trifling mark of my respect and esteem, and a grateful acknowledgment of the many practical lessons which I received from you, while a pupil in that hospital.

\section{"CAse I.}

"John Short, aged 7, of weak, delicate, and scrofulous constitution-previously bealthy-had been lying on wet grass for some hours, two or three days after which he complained of pain in his left hip, referred to the groin and trochanter major; shortly after, the left knee became painful, gradually increasing in intensity, for which (pain in knee) $I$ was requested to visit him on the 20th of August, 1839. On my visit, he had a large poultice applied to the knee, the principal pain being referred to that part, complaining but little of the pain about the hip-joint. On being placed upright, resting on his right hand, the disease presented the following characters :-

"Limb apparently lengthened; knee flexed and advanced forward; limb decreased in size; the left nates appeared tlatter, broader, more protuberant, and elongated; its fold obliterated, and the normal depression behind the trochanter filled up. On gently pressing the trochanter inwards, or tapping the heel, he complained of great pain in the bip-joint. The pains in the knee and hip-joint were much increased in intensity at night, the pain in the former becoming excruciating; frequent starting of the limb, so much so, as to produce the little in. telligent fellow's expression, "I must die if the pain continues " countenance indicative of much suffering; pulse 100 , compressible and weak ; thirst and anorexia.

"I ordered him a scruple of our cathartic powder, which is composed of calomel, aloes, and jalap; to be cupped over the left gluteal region to 8 ounces, and to be afterwards well fomented; and when his bowels had 